\title{
Patterns of vertical specialisation in trade: long-run evidence for 91 countries
}

\author{
Stefan Pahl ${ }^{1} \cdot$ Marcel P. Timmer $^{1}$
}

Published online: 30 May 2019

(c) The Author(s) 2019

\begin{abstract}
The authors estimate the domestic value-added content in exports of manufacturing goods (VAX-D ratio) for 91 countries over the period from 1970 to 2013. They find a strong decline in the world VAX-D ratio since the mid-1980s mostly accounted for by the substitution of foreign for domestic intermediates. Using a breakpoint detection method, they identify three waves of vertical specialisation in the world economy: 1970-1979, 1986-1995 and 1996-2008. The authors find that most countries (79) initiated a period of vertical specialisation at least once. They find strong evidence that the VAX-D ratio correlates negatively with GDP per capita, and that the negative slope is flattening out at higher levels of income.
\end{abstract}

Keywords Vertical specialization - International trade $\cdot$ Economic development

JEL Classification F13 $\cdot$ F14 $\cdot$ F15 $\cdot$ F63 $\cdot$ O19

\section{Introduction}

Countries may specialize in particular stages of production, relying on imports of intermediate goods and services to produce for exports. This process is known as vertical specialisation in trade as proposed by Hummels et al. (2001). Using input-output tables to measure the import content of exports, they found that vertical specialisation increased over the period 1970-1990 in thirteen out of the fourteen countries studied. Yi (2003) showed how the increased interdependence of countries can have major implications for trade policy, for example through cascading effects

Electronic supplementary material The online version of this article (https://doi.org/10.1007/s1029 0-019-00352-3) contains supplementary material, which is available to authorized users.

Stefan Pahl

s.pahl@rug.nl

1 Groningen Growth and Development Centre, Faculty of Economics and Business, University of Groningen, Nettelbosje 2, 9747 AE Groningen, The Netherlands 
of import tariffs and other types of trade protection. Relatedly, Johnson and Noguera $(2012,2017)$ introduced a new metric that measures the value added of a country that is absorbed abroad (expressed as a ratio of gross exports). Based on a panel data set of 42 OECD countries and major emerging markets, Johnson and Noguera (2017) documented a decline in this ratio for almost all countries over the period 1970-2008, interpreted as a widespread process of production fragmentation in the world economy. At the global level, the ratio was falling roughly three times as fast during 1990-2008 compared to 1970-1990.

This paper contributes to the literature on vertical specialisation in two ways: methodologically and empirically. Johnson and Noguera (2017) studied developments in a set of mainly rich and middle-income countries. In this paper we provide new evidence on trends in vertical specialisation in trade for a large set of 91 countries at various stages of development, including many low-income countries, for the period 1970-2013. We also extend the sectoral detail in the data (19 detailed industries, up from 4 broad sectors as in Johnson and Noguera 2017). This puts higher requirements on the data, but improves the measurement and opens the avenue for studying vertical specialisation in the production of particular manufacturing product groups. We track vertical specialisation in trade through the share of domestic value added in gross exports, which we refer to as the VAX-D ratio. ${ }^{1}$ We focus on the exports of manufactured goods which includes value added in the exporting sector, as well as value added from other domestic sectors that contribute through backward linkages. These can be other manufacturing industries, but also non-manufacturing industries delivering primary materials or business and support services. We follow Bai and Perron $(1998,2003)$ and estimate structural breaks in the time series of VAX-D ratios to identify periods of vertical specialisation and vertical integration. Thus we are able to provide an overview of long-run trends in vertical specialisation in trade for a wide set of countries and explore possible correlates, in particular GDP per capita.

Our methodological contribution is in elucidating the difference between an indicator that tracks vertical specialisation, as defined by Hummels et al. (2001), and an indicator that tracks value added absorbed abroad as defined by Johnson and Noguera $(2012,2017)$. The latter has been developed as an alternative measure of exports that fits international trade models that are written in value added terms rather than gross flows (Johnson 2014). Its measurement is built upon tracing forward linkages rather than backward linkages which are central in the concept of vertical specialisation and picked up in VAX-D. The difference between VAX-D and VAX-C measures is not only conceptually, but also empirically relevant. They are quantitatively comparable at the level of aggregate exports, but not at the sectoral level. This is further discussed in Sect. 2 and also highlighted in our results.

The remainder of the paper is structured as follows. In Sect. 2, we discuss the calculation of our main indicator, the VAX-D ratio. We also present our approach to the estimation of structural breaks and the identification of periods of vertical

\footnotetext{
1 This share is equal to (one minus) the import content of export measure of Hummels et al. (2001), see section 2 for discussion.
} 
specialisation. In Sect. 3, we discuss the construction of our dataset. A novelty in our empirical strategy is in using untapped data of value added and gross output in manufacturing in developing countries at a high sectoral disaggregation and annual frequency (UNIDO 2016). This is combined with detailed trade data from Feenstra et al. (2005) and benchmark input-output tables. We present our main findings in Sect. 4. Section 5 concludes.

\section{Methodology}

In this section we first outline our measure of vertical specialisation in trade. Next, we discuss our methodology to identify structural breaks in time-series of this measure following the techniques introduced by Bai and Perron (1998, 2003).

\subsection{Measuring vertical specialisation}

To track vertical specialisation in trade, we measure domestic value added in exports as introduced by Koopman et al. (2012). We follow the terminology of Los and Timmer (2018) and refer to it as the VAX-D ratio. For a particular country, it is defined as

$$
V A X D r_{t}=\frac{V A X D_{t}}{e_{t}^{t o t}}
$$

where $e_{t}^{t o t}$ is the sum of exports, and $t$ a time-subscript. This ratio is bound between zero and one and a lower value indicates a higher level of vertical specialisation in trade. $V A X-D$ is the domestic value added in exports measured as

$$
V A X D_{t}=\mathbf{v}_{\mathbf{t}}^{\prime}\left(\mathbf{I}-\mathbf{Z}_{\mathbf{d o m}, \mathbf{t}}\right)^{-1} \mathbf{e}_{\mathbf{t}}
$$

where $\mathbf{e}$ is a (column) vector of gross exports by industry. There are $n$ industries so $\mathbf{Z}_{\mathbf{d o m}}$ is an $n x n$ matrix of direct domestic input coefficients. Elements $z_{i j}$ of this matrix denote the amount of inputs from domestic industry $i$ needed to produce one unit of output in industry $j$. Further, $\mathbf{I}$ is the identity matrix and $\left(\mathbf{I}-\mathbf{Z}_{\mathbf{d o m}, \mathbf{t}}\right)^{-1}$ the well-known Leontief inverse such that $\left(\mathbf{I}-\mathbf{Z}_{\mathbf{d o m}, \mathbf{t}}\right)^{-1} \mathbf{e}_{\mathbf{t}}$ denotes gross output in all domestic industries that is needed for the production of $\mathbf{e}_{\mathbf{t}}$. It accounts for the fact that the production of a good needs intermediates, which themselves are also produced making use of intermediates, etcetera. The Leontief inverse summarizes all prior production steps as it can be written as a geometric series: $\left(\mathbf{I}-\mathbf{Z}_{\text {dom,t }}\right)^{-1}=\mathbf{I}+\mathbf{Z}_{\text {dom,t }}+\mathbf{Z}_{\text {dom,t }}^{2}+\cdots+\mathbf{Z}_{\mathbf{d o m}, \mathbf{t}}^{\infty}$, under the assumption that the production technology as represented by $\mathbf{Z}$ is the same in all stages of production. To find the domestic value added related to the production of exports, one needs to multiply industry output by the transpose of (column) vector $\mathbf{v}_{\mathbf{t}}$, with element $v_{i}$ the value added over gross output ratio in industry $i$. In our empirical analysis, we focus on domestic value added generated in the production of manufactured exports and exclude exports from mining and agriculture. This is because fragmentation in 
production of these goods is difficult as by nature they contain a large share of location-bound inputs. Thus $\mathbf{e}_{\mathbf{t}}$ contains zeros in all non-manufacturing entries.

Our measure for vertical specialisation is almost identical to the one introduced in the seminal work by Hummels et al. (2001). They proposed to track the import content of exports. Koopman et al. (2012) defined domestic value added in exports and showed that it is equal to gross exports minus the import content of exports. We follow the value added terminology as it has a clearer link with other measures of trade (Johnson 2017; Los and Timmer 2018). VAX-D is related, but different, from the well-known VAX-C measure introduced by Johnson and Noguera (2012). VAX-C tracks the amount of value added in a country that is absorbed abroad. VAX-C was developed as a measure of trade in value added (Johnson 2014). At the aggregate level, VAX-C and VAX-D are equal when the exports of a country consist of final goods only. As most countries also export intermediates VAX-C is typically lower than VAX-D (Koopman et al. 2014; Los et al. 2016). ${ }^{2}$ The numerical difference appears to be generally small as shown in Appendix 3 (Supplementary material) indicating that the share of value added exported through intermediates and returning home is minor. The difference between VAX-C and VAX-D is not necessarily small for sector-level measures however. ${ }^{3}$ VAX-D in manufacturing exports captures all domestic value-added in products exported by the manufacturing sector. This value added is generated in the production chain that includes the manufacturing industry that exports, but also other manufacturing and non-manufacturing industries (such as agriculture, mining and services). In contrast, the manufacturing VAX-C measure of Johnson and Noguera (2017) captures how much value added is generated in the manufacturing industry that is ultimately absorbed abroad, embodied in exports by all industries. ${ }^{4}$ Put otherwise, while the measurement of VAX-C is based on tracing forward linkages in the use of manufacturing value added, VAX-D is based on tracing backward linkages in the production of manufacturing exports (see Los and Timmer 2018 for further discussion). ${ }^{5}$ This is a major conceptual difference and we will show that it matters empirically as well. Hence, the choice of indicator depends crucially on the purpose of the study. VAX-C, for example, lends itself to study demand spillovers through input-output linkages (e.g., Bems et al. 2011). The process of vertical specialization in trade as described by Hummels et al.

\footnotetext{
${ }^{2}$ See Koopman et al. (2014) and Los et al. (2016) who provide a full decomposition of gross exports, encompassing the concept of VAX-D and VAX-C.

3 VAX-C and VAX-D measures also differ for bilateral flows as shown in Los and Timmer (2018). This should not come as a surprise as the two measures have different aims.

4 A sectoral VAX-C ratio can be bigger than one when the sector exports mainly value added through other sectors (see e.g. Table 1 in Johnson and Noguera 2012). A sectoral VAX-D ratio can never be bigger than one, as domestic value added in an export flow can never be bigger than the export flow itself.

5 To construct VAX-C for our set of countries, we would need to construct an integrated multi-region input-output table rather than a set of national input-output tables. Put otherwise, we would need to add information on the country-industry destination of a country's exports. Only then one can trace where a country's value added is ultimately absorbed. This would require additional bilateral trade data and add another layer of complexity to the data construction process (including balancing of trade mirror flows) which we did not attempt here. Using the existing WIOD world input-output tables, we find that the VAX-D and VAX-C measures correlate highly for aggregate exports, see Appendix 3 (Supplementary material).
} 
(2001), however, is about the fragmentation of backward linkages in the production of exports, and therefore we use VAX-D as our measure of vertical specialization in trade.

\subsection{Identifying periods of vertical specialisation}

We define a period of vertical specialisation as a period in which there is a significant trend decline in the VAX-D ratio. To this end, we follow Bai and Perron (1998, 2003) and identify structural breaks in the time series for each country. We proceed in two steps. Firstly, a given maximum number of potential structural breaks is identified in a time series, and secondly the actual number is selected by testing statistical significance of each break.

Let $m$ be a predefined maximum number of structural breaks in a time series. The time periods in between the breakpoints are called "regimes", and are indexed by $i .{ }^{6}$ We will estimate a trend in a given regime $i$ by

$$
\Delta V A X D r_{t(i)}=\alpha_{i}+\varepsilon_{t(i)},
$$

where $t(i)$ indicates year $t$ in regime $i, \triangle V A X D r$ the first-differenced VAX-D ratio (annual observations), $\alpha_{i}$ is a regime-specific constant and $\varepsilon_{t(i)}$ the error term, which is allowed to have different distributions across regimes. This is a pure structural change model in which parameters vary with regimes. To locate break years $T_{i}$ (the last year of regime $i$ ), the following sum of squared residuals is minimized,

$$
\sum_{i=1}^{m+1} \sum_{t(i)}\left(\Delta V A X D r_{t}-\hat{\alpha}_{i}\right)^{2},
$$

with $\hat{\alpha}_{i}$ the estimated parameter obtained from Eq. (3) and t(i) running from $T_{i-1}+1$ through $T_{i}$. The number of breaks $m$ is set before the estimation (we start with 5). In addition one has to choose a minimum length $h$ of a regime. Our choice is guided by the aim to capture long-term developments rather than business cycle fluctuations. We start with $h$ is 5 years. So $\mathrm{t}(\mathrm{i})$ is endogenously pinned down (with minimum distance $h$ ) for a given set of breaks.

Yet, not all breaks might be significant and it is therefore necessary to evaluate in a second step how many break points (and which ones) are preferred. In this second step statistical significance of the breaks is tested. The original Bai and Perron $(1998,2003)$ method suggests two tests: a sequential approach that tests the null of $l$ breaks versus the alternative of $l+1$ breaks, and a global test with the null of no breaks versus the alternative of $l$ breaks. The global test is extended by a "double maximum" test, which searches for the maximized test statistic to choose between the number of breaks that are preferred over no breaks. Bai and Perron (2003) provide asymptotic critical values for these test statistics which are valid for large

\footnotetext{
${ }^{6}$ So there are $m+1$ regimes, including a begin period (up to first breakpoint) and an end period (from last breakpoint to end of period).
} 
sample sizes. In many applications, however, the number of observations is small, which limits the power and size of the tests (Bai and Perron 2006), and thus makes it difficult to identify significant break points. ${ }^{7}$ For this reason Kar et al. (2013) and Pritchett et al. (2016) use the Bai and Peron (1998, 2003) method only to identify potential break points, but subsequently use an ad-hoc filter to decide whether or not to include these.

We prefer to stay more closely to Bai and Perron (2003) approach, acknowledging the potentially weak power and size of the tests. We start with $h=5$ (years) and a maximum of $m=5$ break points in the whole period. Following Bai and Perron (2003), we run the sequential test and the global test to decide on the appropriate number of breaks, using critical values for $p=0.05$. Ideally, both test statistics deliver the same result, that is, the sequential test points to $x$ breaks over $x-1$ and over $x+1$ breaks and the global test rejects zero breaks in favour of $x$ breaks (i.e., we decide for $x$ breaks); or both tests suggest zero breaks (i.e., we decide for zero breaks). This is sometimes not the case. In the case that the global test suggests a positive number of breaks, but the sequential test suggests zero breaks or a number of breaks that is not different from zero breaks in the global test, we decide on the number of breaks using the "double maximum" test statistic in the global test. In the case that the global test suggests zero breaks, but the sequential test suggests a positive number of breaks, we decide for zero breaks (as this indicates that the given number of breaks is not preferred over zero breaks). If we decide for zero breaks, we increase $m$ and decrease $h$ (both by one) to check whether the result of no breaks is sensitive to this choice. If no breaks are confirmed, we stick to no breaks. This is the case for 29 countries. $^{8}$

As the final step, we run regressions for each identified period of the VAX-D ratio on a constant and a linear year trend. If the year trend is negative and significantly different from 0 for $p=0.05$, we categorize it as a period of vertical specialisation. Likewise, when the year trend is positive and statistically significant, we categorize it as a period of vertical integration.

\section{Data sources and construction}

The aim of this paper is to capture long-term trends for a large set of countries. We developed data for 91 countries which is the maximum number of countries for which there is data on detailed industry value added and national accounts data (covering the period from 1970 to 2013). All data was compiled for 14 manufacturing

\footnotetext{
7 Berg et al. (2012) calculate their own sample-specific critical values using Monte-Carlo simulations. They identify almost four times as many break points as compared to using the Bai and Perron (1998, 2003) approach.

${ }^{8}$ For countries that are only covered for shorter periods $(\mathrm{t}<25)$, we use $h=3$. This accounts for the problem that large $h$ will otherwise pin down the location of the break points: e.g., with 20 observations, $h=5$ and $m=4$, each break point has only one possible location. Excluding those countries with shorter periods does not affect the results. 13 of the 15 countries are in Eastern Europe and Central Asia (plus Germany and Yemen).
} 
industries and 5 additional broad sectors, together covering the whole economy, classified by the industrial classification (ISIC) Revision 3.1. It is important to use disaggregated information as industries can differ greatly in their export propensity and value added to gross output ratios. In this section we briefly describe the main characteristics of our data construction, relegating technicalities and validation of the data to an extensive appendix.

Gross exports. Obtaining the export vector $\mathbf{e}$ is relatively straightforward. We follow Johnson and Noguera (2017) to obtain the export vector through combination of aggregate trade levels from United Nations National Accounts Estimates of Main Aggregates (UN 2015b), split into goods and services using IMF Balance of payments statistics (IMF 2018) and across the goods sectors with detailed product-level trade data from Feenstra et al. (2005) and the CEPII-BACI dataset (release 2015; Gaulier and Zignago 2010). We map the goods trade flows to end-use category by use of the broad economic categories (BEC) system. Feenstra et al. (2005) compile recorded trade flows of goods available from UN Comtrade for years until 2008. These data are available in 4-digit SITC Rev.2, which we map to ISIC Rev.3.1, making use of concordance tables obtained from the UN (2015c). The CEPII-BACI dataset provides compiled Comtrade data for the period after 1998, which we use to extend the series from 2009 to 2013 . We use the data in HS96 classification, which we map to ISIC Rev.3.1 using UN concordances.

Value added to gross output ratios. The first challenge in the data construction is to derive consistent time-series of value added to gross output at a detailed industry level (v). Value added and gross output is derived from the UNIDO INDSTAT2 database (UNIDO 2016) for disaggregated manufacturing industries. ${ }^{9}$ To make use of the UNIDO data, we follow the harmonisation strategy of Timmer and De Vries (2009) as series are not consistent: variables are recorded in basic prices or market prices, or even in non-reported valuation. We thus extrapolate and backdate based on series of linked growth rates to obtain consistent time series. Conveniently, this procedure also "repairs" breaks in the series, for example due to changes in the industrial classifications or in the survey methodology used in reporting countries. For other (non-manufacturing) broad sectors, the variables are retrieved from United Nations Official Country Data (UN 2015a) and from United Nations National Accounts Estimates of Main Aggregates (UN 2015b). Importantly, we benchmark value added and gross output at the most recent common year. We then link the series through growth rates and calculate the gross output to value added ratios. This ensures that we derive ratios where both the numerator and the denominator are based on the same sectoral classification and vintage of national accounts data. ${ }^{10}$

Having $\mathbf{v}$ at high (annual) frequency in the data is key to our study. The variable captures amongst others the "fine slicing" of production processes which typically brings down the value added to gross output ratios of the countries involved. In the limit, when all intermediates are imported, the VAX-D ratio equals the valueadded to gross output ratio of the exporting industry. $\mathbf{v}$ would also be available from

\footnotetext{
9 To our knowledge, this is the first attempt to use the UNIDO industrial statistics to construct input-output data.

10 Data for China is complemented by Wu and Ito (2015).
} 
input-output tables but these are typically only available for a limited number of benchmarks years, especially for poorer countries. Fortunately, the UNIDO Indstat database is a comprehensive and reliable international source for industrial statistics that can be used in addition. It provides value added and output series for detailed manufacturing at a high (often annual) frequency, going back to historical years. The UNIDO data is obtained from national statistical agencies, which follow UNIDO's guidelines for definitions (such as the concepts of value added and output) as well as for sampling and data collection. The countries' data is typically based on a sample of medium- and large-scale firms (sampled from the population of firms reported in economic censuses or business registers). A typical sample would include all firms with 5 or 10 employees or more. The questionnaire includes items on payments to primary factors as well as input use. Gross value added is defined and measured as a residual, being gross sales minus intermediate inputs used. Importantly, the inputs include all intermediates such as materials, but also services inputs such as telecommunication or business services costs. As such, it corresponds to the value added concept in the national accounts.

Domestic intermediate input coefficients. The second challenge is in deriving the domestic intermediate input coefficients matrix $\mathbf{Z}_{\mathbf{d o m}}$. These are available for some benchmark years at best and never for long time-periods. Our strategy is to take for each country a benchmark matrix for a particular year, and estimate other years using a technique that makes maximum use of country-specific information that is available (on exports, imports, value added and gross output). For the benchmark matrices we rely on available data from three main international databases that contain national input-output tables: WIOD (Timmer et al. 2015), OECD-TiVA (OECD 2015) and GTAP 7 (Narayanan and Walmsley 2008). We take tables for 34 countries from the WIOD for years 1995-2011, using 1995 as the benchmark year to derive earlier years and 2011 for 2012 and 2013. Additionally, we take tables for another 16 countries from the OECD-TiVA database (benchmark year 2005) and for another 15 countries from the GTAP 7 release (benchmark year 2004). In the online appendix, we list the countries with their respective source of the benchmark tables. ${ }^{11}$ For the remaining 26 countries, we construct a benchmark matrix using country-specific information on exports, imports and sectoral gross output and value added. The interior matrix is approximated using (initial) intermediate input coefficients based on averages for other countries in the region. This approximation procedure is described in the online appendix. The online appendix provides an overview of the countries for which this proxy method was used. Admittedly, the resulting coefficients on the use of intermediate inputs from this procedure are based on approximations, and not on direct observations. Survey data on intermediate input use is scarce and typically not collected in national statistical systems, not even for advanced countries. The

\footnotetext{
11 We use a detailed industry breakdown, yet we might still not pick up heterogeneity across firms within industries. Koopman et al. (2012) show that Chinese firms in export-processing zones have lower VAXD-ratios than other firms in the same industry. When a country's exports are more import-intensive than production for domestic consumption, then an increase in the share of the latter would spuriously suggest declining vertical specialization. Reassuringly, our trend estimates for China are comparable to those made with more detailed data as discussed in Sect. 4.
} 
approximations serve our purpose as they still contain a lot of country- (and year-) specific information due to the use of detailed trade and industry statistics.

Comparison. As an alternative to our data construction, we could have used the "readymade" data in EORA (Lenzen et al. 2013). The current version of EORA provides data from 1990 onwards for a large set of countries. We cover more years in our data, but we also do not use this data source as it has been compiled for global analysis (e.g. of greenhouse gas emissions) and not for more detailed country-level economic analysis. We differ in three major ways from that data set. First, we use a time-varying $\mathbf{v}$ at a high level of industry detail, while ensuring compatibility with national accounts data. Second, we use the structure of an average regional $\mathbf{Z}$ to initiate estimation of the $\mathbf{Z}$ table for those countries for which no table exist. In contrast, EORA is using an average of the $\mathbf{Z}$ structures of Australia, Japan and the USA to estimate the missing tables for all countries, irrespective the level of development of the country. Third, we use a more detailed mapping of intermediate trade flows adding information on end-use from BEC. Arguably each of these procedures is an improvement over the EORA approach and together do justice to a careful treatment of economically important variables and national accounting conventions.

To have a sense of the reliability of our dataset, we compare with the OECD-TiVA database. (release 2018; data for 2005-2016). We find that the rank correlation of the VAX-D ratio in our data set with the OECD-TiVA data (for the countries that are covered in both datasets) is 0.90 . Yet, for the same set of countries, the rank correlation of the VAX-D ratio between OECD-TiVA and EORA is only 0.78. The rank correlation between EORA and OECD-TiVA reduces to 0.75 when using all countries common to both databases. Not surprisingly, the rank correlation between our data set and EORA is also low (0.76). Furthermore, long-run trends in our data on VAX-D ratios for aggregate exports (manufacturing and non-manufacturing) are remarkably close to the data on aggregate VAX-C ratios from Johnson and Noguera (2017) for the 39 countries that are covered in both data sets. This shows that our data construction method delivers results that are in line with other data construction efforts that aim to capture economic phenomena (see online appendix for more).

\section{Empirical findings}

In this section we discuss patterns of vertical specialization in manufacturing exports across countries, which we organize in five main findings. We first present aggregate global trends in VAX-D in Fig. 1. This provides a background for the later analysis of trends in individual countries, and also allow for a comparison with the findings on VAX-C by Johnson and Noguera (2017).

\subsection{Finding 1: Strong declining trend in world VAX-D ratio}

In the upper panel (Fig. 1a) we graph the world VAX-D ratio, defined as the sum of VAX-D across all countries divided by their sum of gross exports. We have data for 74 countries for the period 1970-2013 and for 91 countries for 1995-2010, and we graph both series. The biggest data set additionally includes 17 countries for which 
(a) World VAX-D ratio

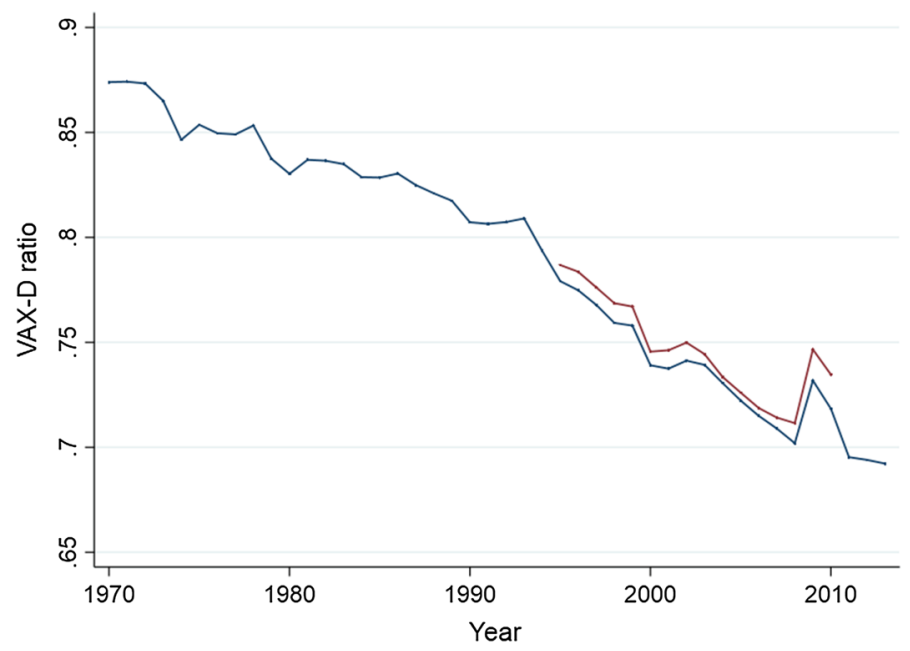

(b) unweighted average across 74 countries

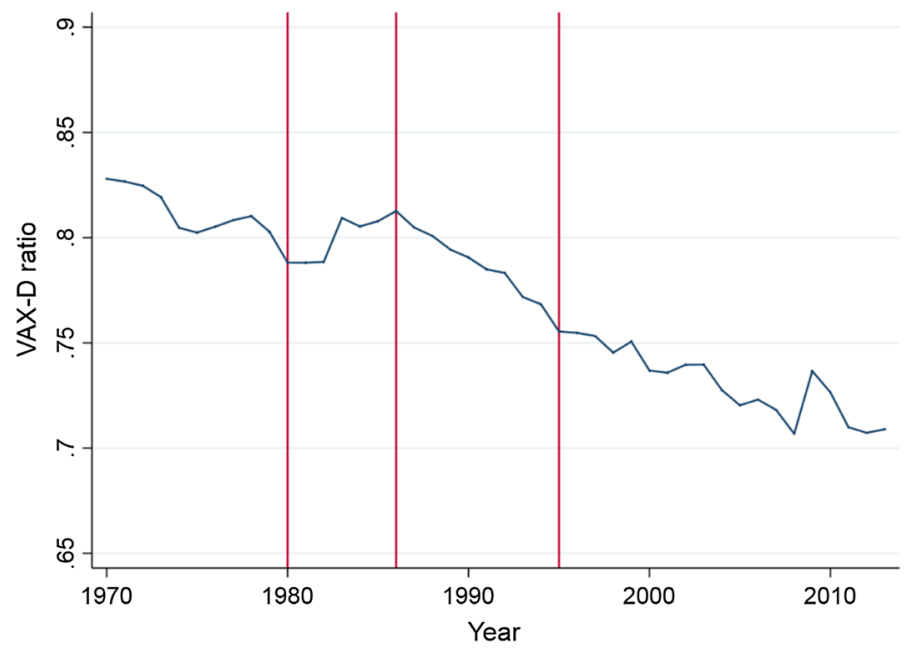

Fig. 1 VAX-D ratio for exports by all manufacturing industries. Note: a World VAX-D ratio is the sum of VAX-D across all countries divided by their sum of gross exports. World VAX-D ratio for 74 countries for 1970-2013 (in blue) and for 91 countries for 1995-2010 (in red). b The unweighted average of VAX-D ratio across 74 countries. Vertical lines indicate significant break points (Bai and Perron 1998, 2003) (colour figure online)

we have shorter time-series, such as, notably, China. The trends are largely comparable though and we focus on the trend in the set of 74 countries. We find a strong declining trend in the VAX-D ratio for manufacturing exports over time, signifying a long-run process of vertical specialisation in the global economy. Using our break point methodology (discussed in Sect. 2) we find that 1994 is a potential break point 


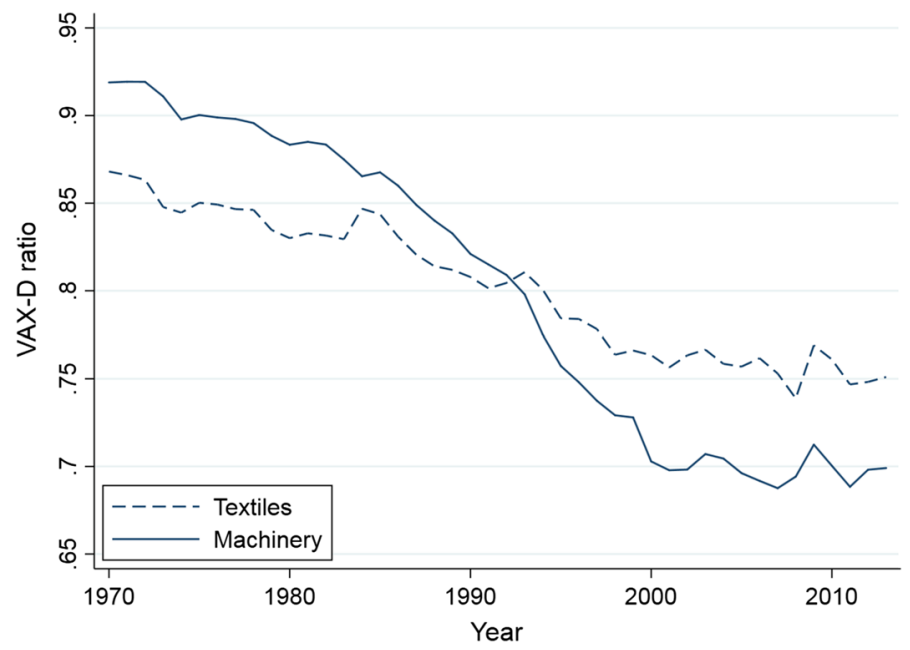

Fig. 2 World VAX-D ratio for exports by machinery and textiles industries. Note: World VAX-D ratio is the sum of VAX-D across 74 countries divided by their sum of gross exports. "Machinery" refers to exports from machinery producing industries, including electronics (industries 29,20,31, 32 and 33 in ISIC rev. 3 classification). "Textiles" refers to exports from the textiles, wearing apparel and footwear producing industries (industries 17, 18 and 19)

year, but the change in the slope turns out to be insignificant. The overall long-run trend is remarkably similar to the trend of the global VAX-C ratio for the manufacturing sector as documented by Johnson and Noguera (2017, Fig. 2c). Their VAX-C ratio (based on 39 countries) declined from 0.64 in 1970 to 0.46 in 2007, while our VAX-D ratio (for 74 countries) declined from 0.88 to 0.71 in the same period. Note that the VAX-D ratio is much larger than the VAX-C ratio. This is mostly due to the conceptual difference between the two measures as discussed in Sect. 2: VAX-D also includes value added in domestic non-manufacturing industries while VAX-C does not. Our dataset also covers more countries, but this is not greatly affecting the world VAX-D share as the volume of exports of the additional countries are minor relative to the exports of the countries already covered in Johnson and Noguera (2017). ${ }^{12}$

We also graph the unweighted average of the VAX-D ratio to have a first impression of the timing of vertical specialisation across individual countries. Figure $1 \mathrm{~b}$ traces the unweighted average for all countries whose series start in $1970(\mathrm{~N}=74)$. The unweighted average is lower than the world VAX-D as the latter is dominated by large countries. Larger countries tend to have higher levels of the VAX-D ratio as they generally have more domestic intermediate input producers to choose from. Our break point methodology suggests four distinct periods. A first period of vertical specialisation is identified from 1970

\footnotetext{
12 VAX-D also includes manufacturing value added that is exported and returns to be domestically absorbed. This difference is minor though, see discussion in Sect. 2.
} 
Table 1 World VAX-D ratio for exports by manufacturing industries

\begin{tabular}{llllllll}
\hline Exporting industry & ISIC rev. 3 & 1970 & 1980 & 1986 & 1995 & 2007 & 2013 \\
\hline Food & $15 \mathrm{t} 16$ & 0.85 & 0.82 & 0.84 & 0.81 & 0.79 & 0.77 \\
Textiles & $17 \mathrm{t} 19$ & 0.87 & 0.83 & 0.83 & 0.78 & 0.75 & 0.75 \\
Wood & 20 & 0.89 & 0.85 & 0.86 & 0.81 & 0.77 & 0.74 \\
Paper & $21 \mathrm{t} 22$ & 0.89 & 0.85 & 0.85 & 0.83 & 0.77 & 0.74 \\
Petroleum & 23 & 0.72 & 0.60 & 0.74 & 0.69 & 0.65 & 0.57 \\
Chemicals & 24 & 0.87 & 0.78 & 0.80 & 0.78 & 0.68 & 0.65 \\
Plastic & 25 & 0.88 & 0.83 & 0.81 & 0.76 & 0.71 & 0.69 \\
Mineral & 26 & 0.89 & 0.84 & 0.86 & 0.84 & 0.79 & 0.76 \\
Metal & $27 \mathrm{t} 28$ & 0.88 & 0.85 & 0.84 & 0.81 & 0.73 & 0.72 \\
Machinery & $29 \mathrm{t} 33$ & 0.92 & 0.88 & 0.86 & 0.76 & 0.69 & 0.70 \\
Transport & $34 \mathrm{t} 35$ & 0.87 & 0.86 & 0.81 & 0.75 & 0.69 & 0.68 \\
Other & $36 \mathrm{t} 37$ & 0.89 & 0.86 & 0.85 & 0.80 & 0.75 & 0.75 \\
\hline
\end{tabular}

World VAX-D ratio is the sum of VAX-D across 74 countries divided by their sum of gross exports

until 1980 (significant negative trend in average VAX-D ratio), followed by a period of vertical integration until 1986 (significant positive trend). From 1986 onwards a period of vertical specialisation starts again which continues in the 1990s, albeit at a slower pace as indicated by a lower slope in trend VAX-D in the period from 1995 onwards. This figure provides quantitative evidence for the conventional narrative that vertical specialisation took off on a global scale in the mid-1980s (Feenstra 1998; Baldwin and Lopez-Gonzalez 2015). The trend was halted in 2009, coinciding with the great global trade slowdown (Bems et al. 2011).

Our detailed data allows us to investigate trends in world VAX-D ratio for exports from twelve manufacturing industries. Table 1 reports the ratios based on data for 74 countries for the 1970-2013 period including break points identified in Fig. 1. It reveals heterogeneity in the level of vertical specialisation as well as in the trends over time. Exports by the petroleum refining industry stand out as being the most import-intensive which is consistent with the fact that many countries need to rely on imported petroleum in the production of refined fuels. Exports by chemical and transport equipment industries are also among the most import-intensive activities, while exports of food rely much more on domestically produced intermediates. All industries (except oil refining) share a long-run decline in the global VAX-D ratio albeit at different speeds. Figure 2 illustrates this heterogeneity. Exports of textiles became gradually more importintensive as the global VAX-D ratio declined from 0.87 in 1970 to 0.75 in 2013. In contrast exports of machinery (including electronics) were below-average intensive in imports in 1970 (0.92), but rapidly becoming more import-intensive over time, and being above-average import-intensive in 2013 (0.70 in 2013). 


\subsection{Finding 2: Substitution of foreign for domestic intermediates accounts for the major part of decline in the world VAX-D ratio}

Heterogeneity in import-intensity across industries opens up the possibility that the decline in the world VAX-D ratio for manufacturing exports which we found in Fig. 1 might be (partly) driven by a shift in the world export mix towards more import-intensive industries. To investigate this we provide a decomposition of the world VAX-D ratio into four components. ${ }^{13}$

This can be thought of as a multi-dimensional variant of the standard withinbetween decomposition of an aggregate ratio (see e.g. Johnson and Noguera 2012). In "Appendix 2", we show how one can decompose the change in the world VAX-D ratio into contributions from (i) shifts in industry export shares (reflected in changes in e), (ii) the substitution between intermediate and primary factor inputs (reflected in changes of $\mathbf{v}$ ), (iii) shifts in the product mix of intermediates (reflected in changes in matrix $\mathbf{Z}$ with product shares in total intermediate use), and (iv) the substitution between imported and domestically produced intermediates (reflected in changes in a matrix $\mathbf{M}$ with import shares of intermediates). This is a meaningful exercise as we have data at annual frequency for each of the components, as discussed in Sect. 2. We compare the quantitative importance of a component by keeping it constant at its value in 1986 while allowing the other components to vary over time. We do this for each component and for each country. We show the world VAX-D ratio across the 74 countries in Fig. 3. We chose 1986 because it is the starting point of the global decline in VAX-D ratios (see Fig. 1).

Figure 3 shows that the substitution of foreign for domestic intermediates accounted for the major part of the decline in the world VAX-D ratio. The solid line in Fig. 3 is based on varying all components and is by construction similar to the world VAX-D ratio shown in Fig. 1a. The decline in the ratio was 0.14 points over the period from 1986 to 2013 . The decline would only be 0.05 points if there had been no substitution of foreign for domestic intermediates (the " $\mathrm{M}$ constant" variant in the figure). Put otherwise, import substitution in intermediates accounted for almost two thirds of the decline in the world VAX-D ratio. The figure also shows that import substitution was the driving force of the sudden increase in the VAX-D ratio from 2008 to 2009, and the subsequent decrease. The other components are quantitatively less important. If the industry export structure had been constant since 1986, the VAX-D ratio would have declined by 0.12 points (e constant variant). This indicates that countries have on average shifted into export of products such as machinery and transport equipment that require relatively more imported intermediates (as shown in Table 2). This export mix effect can account for about $1 / 7$ th of the decline $(0.02 \text { of the } 0.14 \text { points })^{14}$. If the

\footnotetext{
13 We thank a referee for the suggestion to provide a breakdown of VAX-D into various components.

14 Performing this exercise on the unweighted average across the 74 countries, we find a somewhat larger role for export patterns (accounting for $1 / 5$ th of the total decline). This is consistent with the fact that export patterns of developed countries, accounting for the bulk of world gross exports, have changed relatively little since 1986, while those of developing countries have. The role of the remaining factors is qualitatively unchanged.
} 


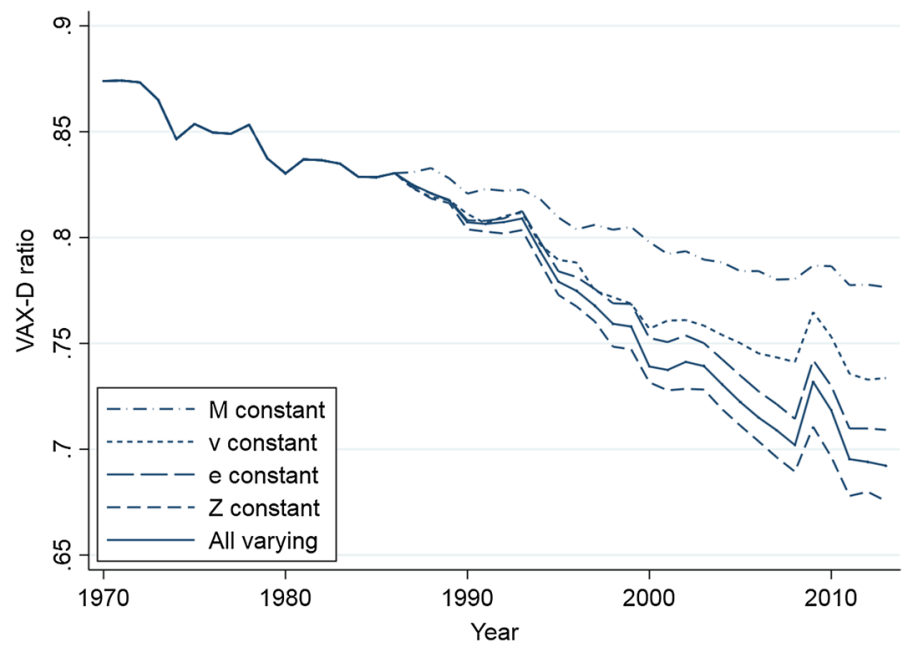

Fig. 3 World VAX-D ratio for exports by manufacturing under alternative scenarios. Note: Authors' calculation based on decomposition of change in VAX-D ratio, see online appendix 4. Lines report alternative VAX-D ratios by keeping a component constant at its 1986 level while varying the other three components. Component $M$ captures substitution between imported and domestically produced intermediates, $v$ captures the substitution between intermediate and primary factor inputs, $e$ captures shifts in industry export shares and $Z$ captures shifts in the product mix of intermediates, see main text

value added to gross output ratios had been constant since 1986, the VAX-D ratio would have declined by 0.10 points ( $\mathbf{v}$ constant variant). It can thus account for about 0.04 of the decline (0.14). It reflects a finer slicing of production processes via outsourcing of production stages such that factor inputs are substituted for intermediates. Finally, we find that if the mix of intermediates had not changed since 1986, the VAX-D ratio would have declined by 0.15 points which is even more than the actual decline of 0.14 ( $\mathbf{Z}$ constant variant). This suggests that the product mix of intermediates has shifted towards intermediates that are produced domestically rather than imported. This is consistent with an increasing importance of domestic services in production of manufactured goods, also known as the servicification of manufacturing (e.g., Miroudot and Cadestin 2017).

In the remainder of the paper, we show that the global average hides substantial variation in the timing and the strength of trends across individual countries. We organise the discussion of the results around three other main findings.

\subsection{Finding 3: Three waves of vertical specialisation in the world economy}

We have annual data on the VAX-D ratios for 91 individual countries and trace for each country-year whether it is in a period of vertical specialisation (VS) as defined in Sect. 2. The country-year is in a period of VS when the year is in a period where the trend in the VAX-D ratio for the country is negative and significantly different from 0. Detailed annual results are given in the online appendix A4. In Table 2 we 
Table 2 Share of country-years in periods of vertical specialisation

\begin{tabular}{|c|c|c|c|c|c|c|c|}
\hline \multirow{2}{*}{$\begin{array}{l}\text { Country } \\
\text { group }\end{array}$} & (1) & (2) & (3) & (4) & (5) & (6) & (7) \\
\hline & \# Countries & $\begin{array}{l}\text { \# Coun- } \\
\text { tries with } \\
\text { VS }\end{array}$ & 1970-1979 & 1980-1985 & 1986-1994 & 1995-2008 & 2009-2013 \\
\hline $\begin{array}{l}\text { All coun- } \\
\text { tries }\end{array}$ & 91 & 79 & 59.0 & 52.7 & 61.5 & 57.9 & 47.7 \\
\hline Developed & 18 & 18 & 85.9 & 71.6 & 78.3 & 78.2 & 66.7 \\
\hline Developing & 73 & 61 & 51.0 & 47.3 & 56.9 & 52.9 & 42.7 \\
\hline $\begin{array}{l}\text { East and } \\
\text { South } \\
\text { Asia }\end{array}$ & 10 & 10 & 80.7 & 62.7 & 68.9 & 44.9 & 31.9 \\
\hline $\begin{array}{l}\text { South } \\
\text { America }\end{array}$ & 8 & 8 & 40.0 & 52.1 & 81.9 & 67.9 & 62.5 \\
\hline $\begin{array}{l}\text { Central } \\
\text { America }\end{array}$ & 9 & 7 & 44.4 & 44.4 & 60.5 & 51.6 & 55.6 \\
\hline $\begin{array}{l}\text { Sub-Saha- } \\
\text { ran Africa }\end{array}$ & 11 & 9 & 63.6 & 63.6 & 64.6 & 59.1 & 54.5 \\
\hline $\begin{array}{l}\text { Mid. East } \\
\text { and N. } \\
\text { Africa }\end{array}$ & 15 & 9 & 34.3 & 21.4 & 28.5 & 31.9 & 20.0 \\
\hline $\begin{array}{l}\text { Eas. Eur. } \\
\text { and Centr. } \\
\text { As. }\end{array}$ & 20 & 18 & 48.6 & 50.0 & 54.2 & 64.2 & 45.0 \\
\hline
\end{tabular}

Shares derived by count of country-year observations which are in period with significant decline in the VAX-D ratio (indicated by "-_" in Appendix Table 4) divided by all country-year observations in a period. Periods identified by break points and trend in VAX-D ratios as described in main text (for $p=0.05$ ), see section 2. Data from Appendix Table 4 in the appendix

summarize the results by regional grouping and by period. We chose the periods suggested by the structural breaks in Fig. 1. Geographical regions are indicated to the left, and the total number of countries in the respective region in column (1). Column (2) indicates how many countries in the region initiated at least one period of VS. We find that 79 out of the 91 countries initiated a period of VS at some point during 1970-2013. Results in columns (3)-(7) present the number of countryyear observations in a period of VS as a share of all country-year observations in the group. For example, of all country-years observations between 1970 and 1979, $59.0 \%$ are in a country with a period of VS.

The results in Table 2 suggest three different waves of vertical specialisation in the world economy. The first wave was in the 1970s which involved almost all developed countries ( $86 \%$ of the country-year observations) and the majority of countries in East and South Asia (81\%) as well as Sub-Saharan Africa (64\%) in our data set. The second wave started in the second halve of the 1980s (1986-1994) and was more wide spread now also involving countries in South America (82\%) and Central America (61\%). It was followed by a third wave (1995-2008) with a concentration of 
the VS process as the share at the global level dropped from 62\% during 1986-1994 to 58\% during 1995-2008. Developed countries were still heavily involved, but there was a sharp drop in the share for East and South Asia (from 69 to 45\%) as well as for South America and Central America. Countries in Eastern Europe and Central Asia became more involved however, as the share increased from 54 to 64\%. Countries in the Middle East and North Africa experienced relatively few periods of VS with shares well below $40 \%$ in any period. ${ }^{15}$

\subsection{Finding 4: A period of vertical specialisation is occasionally followed by vertical integration}

Most countries initiate a period of vertical specialisation, increasingly relying on imports to produce for exports. It is sometimes hypothesized that a period of vertical specialisation will be followed by a period of vertical integration as a country successfully develops capabilities for domestic production of intermediates. China is often cited as a prime example of this development pattern (see discussion below). Vertical specialisation followed by vertical integration might be a more general phenomenon for countries that become richer, related to the finding of Imbs and Wacziarg (2003) that over the course of development production structures of countries first concentrate and later on diversify such that a larger share of inputs can be sourced domestically. We test whether this reversal is found for more countries. To do so, we track for each country that initiated a period of VS whether it continued (the VAX-D trend is strictly monotonic), was followed by a period with non-significant trends in the VAX-D ratio (the trend is monotonic) or was followed by a period with significant positive trends in the VAX-D ratio (the trend is non-monotonic). The number of countries that fall into these three bins are given in columns (2) through (4) of Table 3. Column (1) indicates the number of countries in each region that initiated VS (repeating column 2 of Table 2 for convenience).

The main finding from Table 3 is that vertical specialisation is often not strictly monotonic: of the 79 countries that initiated VS, only 31 had strictly monotonic trends; 23 had monotonic trends; and 25 countries had non-monotonic trends. The number of countries with non-monotonic trends is relatively higher in the group of developing countries. In particular, we find such non-monotonic patterns in East and South Asia, where six out of ten countries experience non-monotonic patterns. There are also six (out of eighteen) countries in Eastern Europe and Central Asia with upward trends in VAX-D. The upward trends in VAX-D ratios often appear in the mid-1990s (see also Table 1). ${ }^{16}$

\footnotetext{
15 Results based on a less stringent rule for the identification of break points ( $p$ value of 0.10 instead of $0.05)$ are qualitatively the same and available upon request. Excluding countries with short time periods $(\mathrm{t}<25)$ does also not alter the results. For columns (3) to (7), we obtain shares for all countries of 59.0, 52.7, 62.0, 56.6, 51.1. 13 of the 15 excluded countries are in Eastern Europe and Central Asia.

16 We also based break point identification under $p=0.10$ rather than $p=0.05$. We identify nine more countries with non-monotonic trends (in total 34 out of 82). Excluding countries with shorter time periods $(\mathrm{t}<25)$, we find 30 in column (2), 17 in column (3), and 19 in column (4). 13 of the 15 excluded countries are in Eastern Europe and Central Asia.
} 
Table 3 Number of countries by trend in VAX-D ratios

\begin{tabular}{lcllr}
\hline Country group & $(1)=(2)+(3)+(4)$ & \multicolumn{2}{l}{ Trend in VAX-D ratio } & \\
\cline { 3 - 5 } & & Strictly & Monotonic & Non-monotonic \\
& & $(2)$ & $(3)$ & $(4)$ \\
\hline All countries & 79 & 31 & 23 & 25 \\
Developed & 18 & 11 & 4 & 3 \\
Developing & 61 & 20 & 19 & 22 \\
East and South Asia & 10 & 2 & 2 & 6 \\
South America & 8 & 5 & 2 & 1 \\
Central America & 7 & 4 & 0 & 3 \\
Sub-Saharan Africa & 9 & 5 & 1 & 3 \\
Mid. East and N. Africa & 9 & 1 & 5 & 3 \\
Eas. Eur. and Centr. As. & 18 & 3 & 9 & 6 \\
\hline
\end{tabular}

Trends in VAX-D ratio in each country for periods as identified through break points $(p=0.05)$, see section II. Each country had at least one period of significant decline in VAX-D ratio (VS). If the following years are also in a period of VS, then the trend is classified as "strictly monotonic". When it is followed by a period with a significant upward trend in VAX-D ratio then it is classified as "non-monotonic". Otherwise it is classified as "monotonic". Data as given in Appendix Table 4

To explore the sources of non-monotonicity, we investigate four countries with a major trend break in their VAX-D ratios. Figure 4 shows the VAX-D ratios of Bangladesh, China, Malaysia and the Philippines. In Table 4, we complement the graphs with decompositions of the identified periods of increasing VAX-D ratios. This relies on a decomposition into four components also used in Fig. 2 (see "Appendix 2" for details). Columns (2)-(5) give the absolute contributions of each of the components (they sum up to column 1), and columns (6)-(9) the relative contributions (they sum up to $100 \%$ ). In all four cases, we find that the substitution of domestic for foreign intermediates played the major role in driving the increase in the VAX-D ratio, after an initial decline.

Figure 4a depicts the VAX-D ratio for China. We find a trend reversal in 2005 when a period of decline in the ratio since the end of the 1990s turns into an increase. This confirms the findings of various other studies. Koopman et al. (2012) and Duan et al. (2018) demonstrated an increase in the domestic content of exports from China over the 2000s relying on information from input-output tables. Kee and Tang (2016) and Brandt et al. (2017) reported declining shares of foreign intermediate use with firm-level data. We find that the VAX-D ratio increased by 0.084 over the period 2005-2010, of which 0.082 points is due to the substitution of domestic for foreign intermediates. It fits the narrative of local firms in China that started to specialise in assembly of imported materials in the 1990s, providing them access to markets and technology. Gradually, some firms took over more upstream production 
(a) China

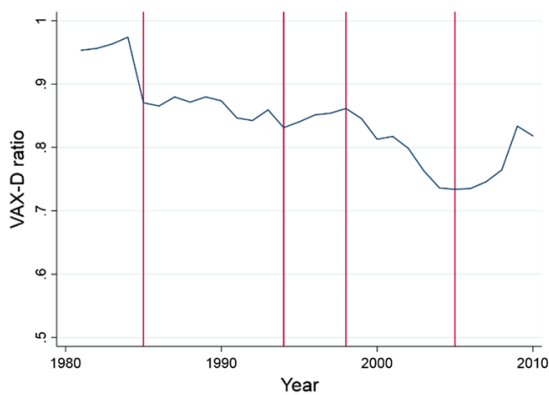

(c) Malaysia

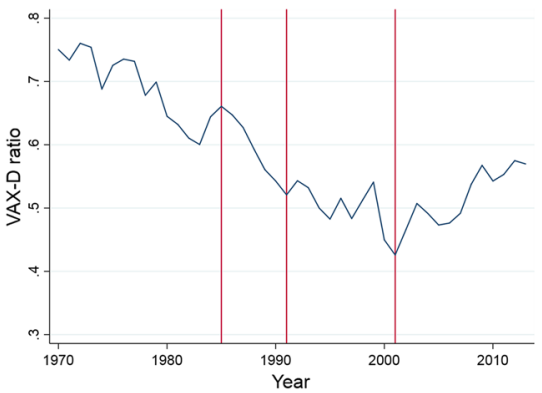

(b) the Philippines

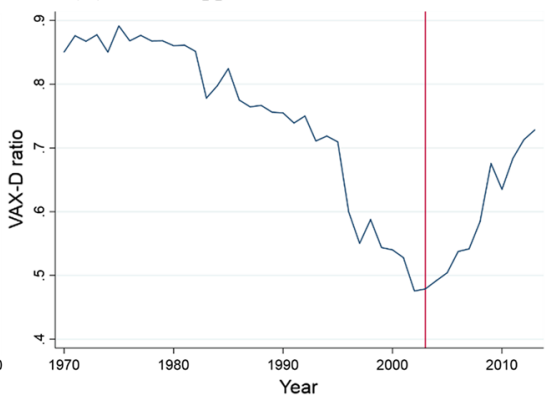

(d) Bangladesh

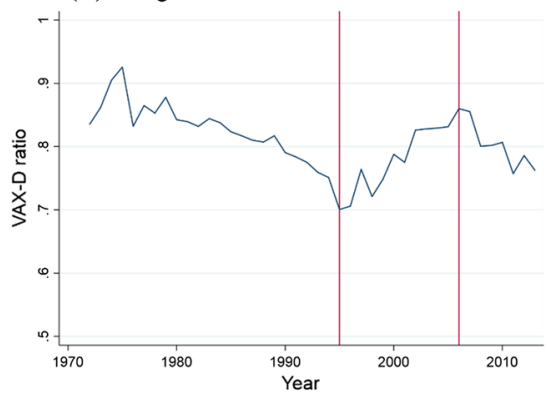

Fig. 4 Examples of countries with non-monotonic trends in VAX-D ratio. Note: Vertical lines indicate break points (Bai and Perron 1998, 2003)

stages building upon domestic learning and innovation, decreasing dependence on imported intermediates. ${ }^{17}$

Malaysia and the Philippines both had a long period of vertical integration. As in China, the substitution of foreign for domestic intermediates contributed substantially in both countries. For the Philippines, we find an increase in the VAX-D ratio of 0.249 between 2003 and 2013 of which 0.130 is due to changes in the substitution of foreign for domestic intermediates. Yet additionally to that, the Philippines also substituted intermediates for primary factors contributing substantially to the increase in the VAX-D ratio (0.107). For Malaysia, we find an increase of 0.144 between 2001 and 2013 of which 0.084 is due to the substitution of foreign for domestic intermediates. Equally important is the shift into exporting by industries that require relatively fewer imported intermediates (0.083). For Bangladesh, we find an increase of the VAX-D ratio of 0.159 between 1995 and 2006. As in China, this is largely due to the substitution of domestic for foreign intermediates. In fact, it accounts for even more than the actual change $(0.189)$ as the mix of intermediates shifted into products are more import-intensive (contributing -0.065). Figure $3 \mathrm{~d}$ shows that in 2006 a new period of vertical specialisation was initiated. We

17 It should be noted that we are not able to distinguish between export processing and ordinary production which differ substantially in their import content (Koopman et al. 2012). Using richer data, Kee and Tang (2016) and Duan et al. (2018) also document the prominent role of substitution of domestic for imported intermediates in China's rising VAX-D ratio. 


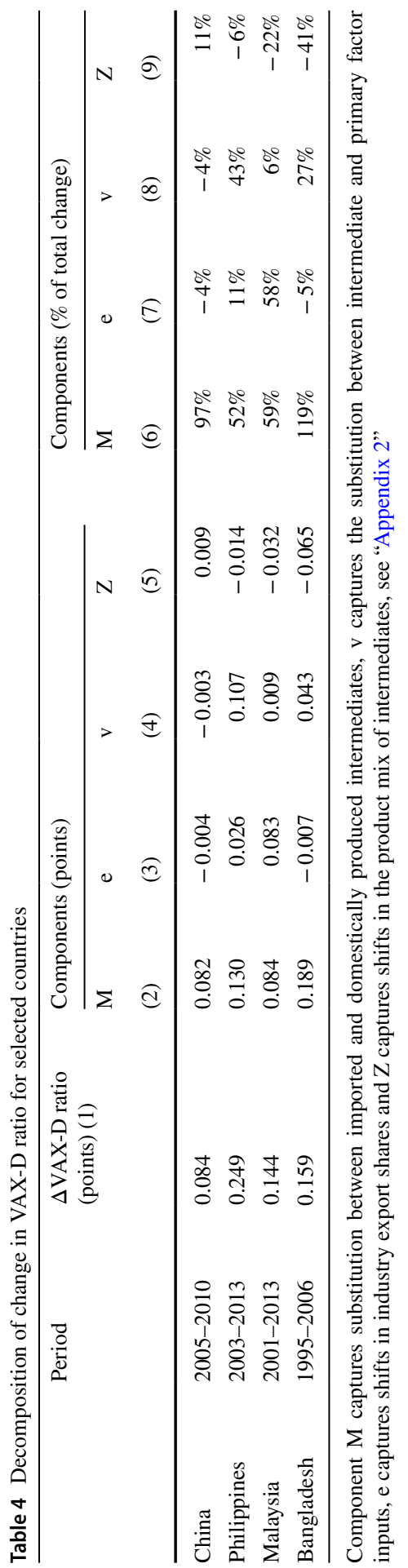


also analysed trends in the other (eighteen) developing countries that experienced a period of increasing VAX-D ratio after initiating vertical specialisation. We find that in fourteen cases the largest contribution to the increase was through substitution of domestic for foreign intermediates.

Overall, our results show that the decline in VAX-D ratios is not always (strictly) monotonic, and that non-monotonicity often tends to be driven by substitution of domestic for imported intermediates. In the next section, we explore more formally possible correlates of the VAX-D ratio, and focus in particular on levels of development, proxied by GDP per capita.

\subsection{Finding 5: VAX-D ratio correlates negatively with GDP per capita}

The recent empirical findings on Chinese development are sometimes used to suggest the existence of a U-curve relationship between the VAX-D ratio and GDP per capita. In an early phase of development, poor countries may start exporting relying on imported goods and services. During the course of further development, they might gradually substitute domestic for imported intermediates as local capabilities increase. The U-curve hypothesis is not new and has its origins in early work on structural change by Hirschman (1958) and later on by Chenery et al. (1986). A recent formulation is provided in Milberg et al. (2014). We investigate the hypothesis in a simple descriptive regression as:

$$
V A X D r_{i t}=\beta_{0}+\beta_{1} \ln Y_{i t}+\beta_{2}\left(\ln Y_{i t}\right)^{2}+D_{i}+\varepsilon_{i t},
$$

where $i$ and $t$ correspond to country and year, VAXDr defined as above, $Y$ is the output-based real GDP at chained PPPs divided by population (from PWT 9.0, Feenstra et al. 2015) and $\varepsilon_{i t}$ is the error term assumed to be i.i.d. Country dummies $D_{i}$ account for average country-level differences in the level of the VAX-D ratio. For example, larger countries tend to have higher levels of the VAX-D ratio as they generally have a larger number of domestic intermediate input producers to choose from. This is the baseline regression. We subsequently add time dummies, and measures for human capital and physical capital per worker (both from PWT 9.0, Feenstra et al. 2015). We test for the U-curve following Lind and Mehlum (2010). The main insight from Lind and Mehlum (2010) is that a significant positive coefficient $\beta_{2}$ is only a necessary but not sufficient condition for a convex (U-curve) relationship. It is also necessary to test for the slopes on both sides of the extreme point to reject a monotone relationship. The slopes are evaluated at the minimum and maximum of the observed data range. ${ }^{18}$ We present the test results in the regression table, and indicate whether the slopes at the minimum and maximum are statistically different from zero.

\footnotetext{
18 In the model $y_{i}=\beta_{0}+\beta_{1} x_{i}+\beta_{2} x_{i}^{2}+\varepsilon_{i}$, the combined null hypothesis is thus $\beta_{1}+2 \beta_{2} x_{\min } \geq 0$ and/ or $\beta_{1}+2 \beta_{2} x_{\max } \leq 0$, and is tested versus the alternative $\beta_{1}+2 \beta_{2} x_{\min }<0$ and $\beta_{1}+2 \beta_{2} x_{\max }>0$. $x_{\text {min }}$ and $x_{\max }$ are the minimum and maximum in the data range.
} 
Table 5 Vertical specialisation and GDP per capita. Dependent variable: VAX-D ratio

\begin{tabular}{|c|c|c|c|c|c|c|}
\hline Variables & (1) & (2) & (3) & (4) & $(5)$ & (6) \\
\hline $\begin{array}{l}\text { GDP per capita } \\
\quad(\ln )(Y)\end{array}$ & $\begin{array}{l}-0.0183 \\
(0.0361)\end{array}$ & $\begin{array}{l}-0.129 * * * \\
(0.0442)\end{array}$ & $\begin{array}{l}-0.0572 \\
(0.0422)\end{array}$ & $\begin{array}{l}-0.130 * * * \\
(0.0452)\end{array}$ & $\begin{array}{l}-0.151 * * * \\
(0.0473)\end{array}$ & $\begin{array}{l}-0.103 * * \\
(0.0519)\end{array}$ \\
\hline Y square & $\begin{array}{l}-0.00389 * \\
(0.00200)\end{array}$ & $\begin{array}{l}0.00171 \\
(0.00246)\end{array}$ & $\begin{array}{l}0.00199 \\
(0.00233)\end{array}$ & $\begin{array}{l}0.00618 * * \\
(0.00248)\end{array}$ & $\begin{array}{l}0.00713 * * * \\
(0.00252)\end{array}$ & $\begin{array}{l}0.00465^{*} \\
(0.00282)\end{array}$ \\
\hline $\begin{array}{l}\text { Human capital } \\
\text { (ln) }\end{array}$ & & & & $\begin{array}{l}0.180 * * * \\
(0.0317)\end{array}$ & $\begin{array}{l}0.184 * * * \\
(0.0321)\end{array}$ & $\begin{array}{l}0.235 * * * \\
(0.0347)\end{array}$ \\
\hline $\begin{array}{l}\text { Physical capital } \\
\text { (ln) }\end{array}$ & & & & & $\begin{array}{l}0.00249 \\
(0.00588)\end{array}$ & \\
\hline Constant & $\begin{array}{l}1.417 * * * \\
(0.163)\end{array}$ & $\begin{array}{l}1.960 * * * \\
(0.199)\end{array}$ & $\begin{array}{l}1.346^{* * * *} \\
(0.194)\end{array}$ & $\begin{array}{l}1.533 * * * \\
(0.200)\end{array}$ & $\begin{array}{l}1.614 * * * \\
(0.201)\end{array}$ & $\begin{array}{l}1.370 * * * \\
(0.230)\end{array}$ \\
\hline Observations & 3094 & 1986 & 1986 & 1986 & 1951 & 1986 \\
\hline $\begin{array}{l}\text { Adjusted } \\
\text { R-squared }\end{array}$ & 0.755 & 0.771 & 0.806 & 0.810 & 0.811 & 0.811 \\
\hline Time dummies & No & No & Yes & Yes & Yes & Yes \\
\hline Sample & Full & Poor & Poor & Poor & Poor & Poor, non-serv \\
\hline \multicolumn{7}{|c|}{ Lind and Mehlum (2010) test } \\
\hline Extreme point & n.a. & n.i. & n.i. & 36,967 & 39,698 & 59,874 \\
\hline Slope at $\min$ & & $-0.108 * * *$ & $-0.033 * * *$ & $-0.055^{* * *}$ & $-0.065^{* * *} *$ & $-0.046^{* *}$ \\
\hline Slope at max & & $-0.088 * * *$ & -0.010 & 0.018 & 0.020 & 0.009 \\
\hline$P$ value & & & & $p=0.13$ & $p=0.12$ & $p=0.30$ \\
\hline
\end{tabular}

Poor sample excludes countries that are member of the OECD in 1970 and countries that generate on average more than 5\% of GDP through oil rents. Human and physical capital on a per worker basis from PWT (Feenstra et al. 2015), Column (6) is based on alternative measure of the VAX-D ratio excluding the domestic services content from exports (see main text). N.a. indicates that Lind-Mehlum test is not applicable. n.i. indicates that extreme point is not in interval. Extreme points are in 2011 US\$. Clusterrobust standard errors to heteroscedasticity in parentheses. ${ }^{* * *} p<0.01 ; * * p<0.05 ; * p<0.1$. All regressions include country dummies

We first run the regression for the full data set. Results are given in column (1) of Table 5. We find a negative relationship between the VAX-D ratio and GDP per capita and no evidence for a U-curve as the quadratic term has a negative coefficient. This result might be driven by the developments in already rich countries and does not preclude a U-curve in earlier stage of developments. We subsequently focus on a sub-set of the countries by excluding countries that were OECD members in 1970 and oil-dependent countries, defined as countries that accrue, on average, more than $5 \%$ of their GDP from oil rents. ${ }^{19}$ We find support for a U-curve (column 2) but the turning point is well outside the maximum of the GDP per capita levels in the sample. Consequently, the slope is significantly negative for the minimum as well as the maximum in our data range. We further include time dummies for global trends that are possibly shared across countries as suggested in the previous sections (column 3). This improves the explanatory power of the model and we find again evidence for a

\footnotetext{
19 We obtain the share of oil rents from the World Bank (2018a), and calculate the average over the available time period in the World Bank data. We thus exclude Azerbaijan, Algeria, Ecuador, Egypt, Gabon, Kuwait, Nigeria, Oman, Qatar, Russia, Saudi Arabia, Syria, and Trinidad and Tobago.
} 
U-curve such that the slope flattens with higher GDP per capita but the turning point is still outside the data range. We subsequently add (ln) human capital per worker (column 4). Interestingly, we find a significantly positive impact of human capital on the VAX-D ratio consistent with the idea that the development of domestic capabilities to produce intermediates that can substitute for imports requires advancing skills of the work force. We again find a convex relationship between the VAX-D ratio and GDP per capita with a turning point at 36,967 in 2011 US\$. This turning point is near the maximum of the data range with only about $1 \%$ of the observations to the right of it. Accordingly, the Lind and Mehlum (2010) test statistic does not reject a linear relationship $(p=0.13)$ and the slope at the maximum is not statistically different from zero. In column (5), we additionally control for (ln) physical capital per worker, but the results are barely affected. Finally, we run the regression with an alternative VAX-D that only tracks value added that is produced outside the domestic services sector. This is to check whether the increase in VAX-D in a later stage of development is mostly driven by an increasing services content of manufacturing exports. Running the regression on the non-services VAX-D ratio (column 6), we find that the turning point shifts further to the right such that only Singapore is to the right of the turning point. ${ }^{20}$

Overall, we conclude that the VAX-D ratio is negatively correlated with GDP per capita. We do not find evidence for a U-curve relationship, even when we restrict our sample to developing (non-oil and non-OECD) countries. At best, there is some weak evidence that the negative slope is flattening out at higher levels of income.

\section{Concluding remarks}

In this paper we analysed for the first time long-run trends in vertical specialisation for a large set of countries at a wide range of income levels. This is based on a newly constructed database that allows estimation of the domestic value-added content in exports of manufacturing goods (VAX-D ratio) for 91 countries over the period from 1970 to 2013. We documented five main findings. First, we found a strong decline in the world VAX-D ratio of manufactured exports since the mid-1980s. This trend was particularly strong for durable goods like machinery and transport equipment as well as chemical products. Second, a decomposition showed that the substitution of foreign for domestic intermediates accounted for more than half of this decline. Substitution of intermediates for primary factors and changes in the export mix accounted for the remainder. Third, using a breakpoint detection method, we found three waves of vertical specialisation in the world economy. The first wave (1970-1979) involved almost all developed countries and the majority of countries in East and South Asia as well as SubSaharan Africa in our data set. The second wave (1986-1994) was more wide spread also involving countries in South and Central America. The third wave (1995-2008) revealed a concentration of the vertical specialization process as there was a sharp drop

\footnotetext{
${ }^{20}$ We also run the specification with a cubic function of GDP per capita. We find qualitatively similar results as the coefficient of the linear term is positive, the quadratic term is negative and the cubic term is positive.
} 
for East and South Asia as well as for South and Central America. On the other hand, countries in Eastern Europe and Central Asia became more involved.

Our fourth finding is that almost all countries (79 out of 91) initiated a period of vertical specialisation as indicated by a period of significantly declining VAX-D ratio. Often this decline continued (in thirty-one countries) or was followed by a non-significant trend in the VAX-D ratio (twenty-three countries). Yet, occasionally it was followed by a period of vertical integration: twenty-five countries experienced an increase in the VAX-D ratio after an initial decline. In our final analysis, we investigate the relationship between the VAX-D ratio and GDP per capita in a formal regression analysis. We find strong evidence that the VAX-D ratio correlates negatively with GDP per capita, and that the negative slope is flattening out at higher levels of income. We do not find evidence for a U-curve relationship though, even when we restrict our sample to developing (non-oil and non-OECD) countries.

These stylised facts provide a start for further analysis into the causes and consequences of vertical specialisation in trade. Johnson and Noguera (2017) found that trade costs and international trade agreements are obvious candidates to determine cross-border production sharing. This was based on a study of mainly mature economies. With our new data on developing countries, this can be re-investigated. It also opens the avenue for a further characterisation of international trade beyond value added flows and vertical specialisation. Timmer et al. (2018) study functional specialization in trade based on metrics that track not only the value added, but also the type of activity a country performs when exporting. They find specialisation of advanced countries in R\&D activities, and specialisation of developing countries in fabrication activities. Another line of research is in investigating the impact of trade specialisation on the performance of firms, such as in studies on African firms by Del Prete et al. (2017) and Foster-McGregor et al. (2014). We hope that our new dataset and findings will stimulate further research on these important issues in international trade.

Acknowledgements Financial support from the Dutch Science Foundation (NWO) for both authors is gratefully acknowledged (Grant Number 453-14-012). We are thankful to anonymous referees, colleagues, seminar audiences and conference participants around the world providing valuable comments and feedback on earlier drafts of this paper.

Data availability The data supporting the findings of this study are available within the article's supplementary materials. It includes yearly data of the VAX-D ratio, value added in manufacturing exports and gross exports of 91 countries with 12 manufacturing industries between 1970 and 2013.

Open Access This article is distributed under the terms of the Creative Commons Attribution 4.0 International License (http://creativecommons.org/licenses/by/4.0/), which permits unrestricted use, distribution, and reproduction in any medium, provided you give appropriate credit to the original author(s) and the source, provide a link to the Creative Commons license, and indicate if changes were made.

\section{Appendix 1: Countries and industries in the database}

See Tables 6 and 7. 


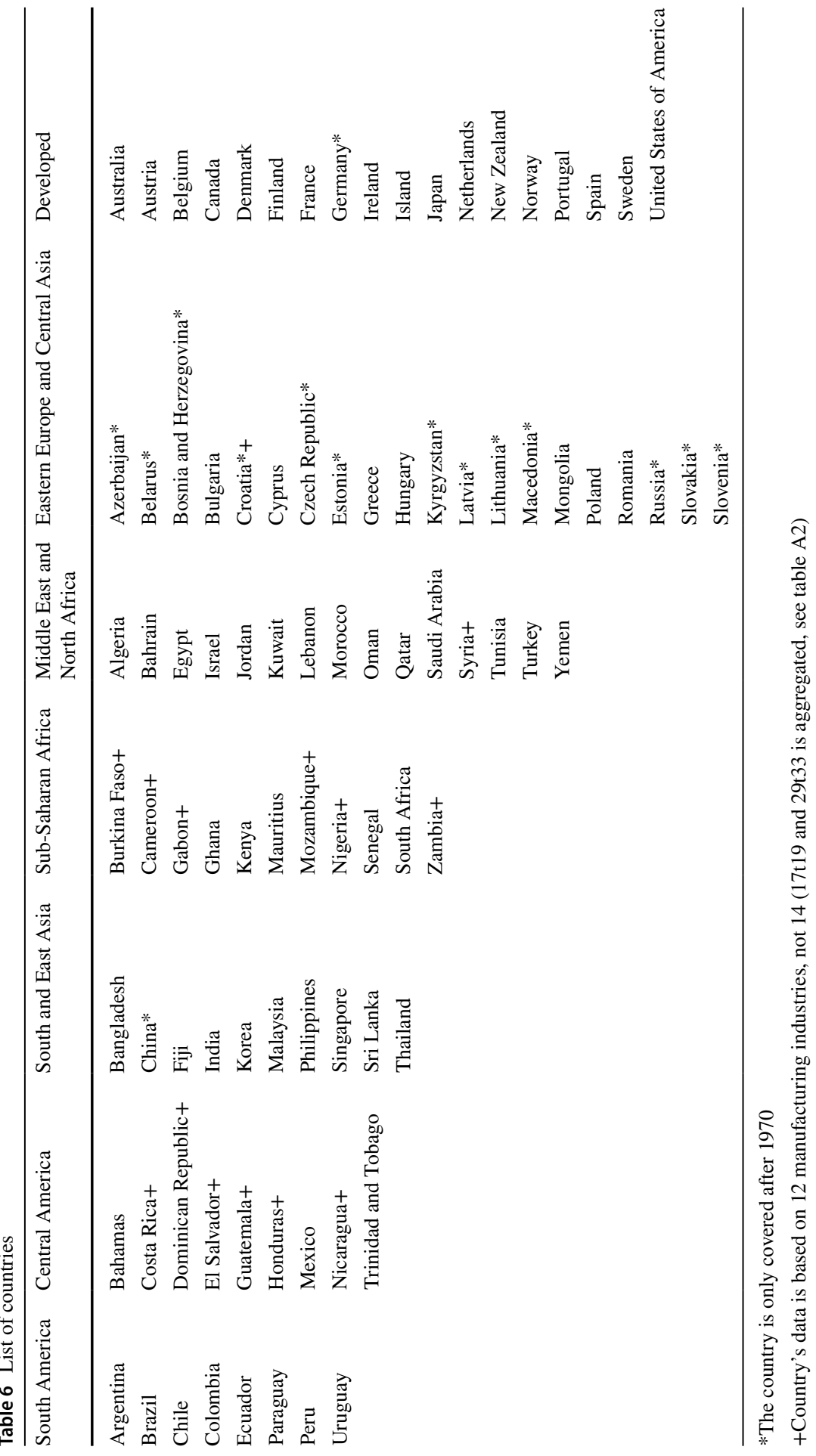


Table 7 List of sectors

\begin{tabular}{ll}
\hline ISIC Rev.3.1 & Description \\
\hline AtB & Agriculture, Hunting, Forestry and Fishing \\
C; E & Mining and Quarrying; Electricity, Gas and Water Supply \\
$15 \mathrm{t} 16$ & Food, Beverages and Tobacco \\
$17 \mathrm{t} 18$ & Textiles and Textile Products \\
19 & Leather and Footwear \\
20 & Wood and Products of Wood and Cork \\
$21 \mathrm{t} 22$ & Pulp, Paper, Printing and Publishing \\
23 & Coke, Refined Petroleum and Nuclear Fuel \\
24 & Chemicals and Chemical Products \\
25 & Rubber and Plastics \\
26 & Other Non-Metallic Mineral \\
$27 \mathrm{t} 28$ & Basic Metals and Fabricated Metal \\
29 & Machinery, n.e.c. \\
$30 \mathrm{t} 33$ & Electrical and Optical Equipment \\
$34 \mathrm{t} 35$ & Transport Equipment \\
$36 \mathrm{t} 37$ & Manufacturing, n.e.c. \\
F & Construction \\
I & Transport Activities; Post and Telecommunications \\
Services & Other Services \\
\hline & \\
\hline & \\
25 & \\
\hline
\end{tabular}

\section{Appendix 2: Decomposition of change in VAX-D ratio}

This section shows the accounting decomposition applied in Sect. 2 of the main text. The decomposition follows Duan et al. (2018) based on the polar form decomposition introduced by Dietzenbacher and Los (1998). We can rewrite the formula of the VAX-D ratio as

$$
V A X D r_{t}=\mathbf{v}_{\mathbf{t}}^{\prime}\left(\mathbf{I}-\mathbf{Z}_{\mathbf{d o m}, \mathbf{t}}\right)^{-1} \mathbf{e}_{\mathbf{t}}^{\mathbf{S}}
$$

where $\mathbf{e}_{\mathbf{t}}^{\mathbf{S}}$ depicts the industry shares in total exports (such that the elements sum to one). We drop the time subscripts from hereon for readability. We will rewrite the right side of the equation, such that it consists of four distinct components: (i) substitution of primary and intermediate factors (vector $\mathbf{v}$ ), (ii) substitution of foreign and domestic intermediate use (to be defined through matrix $\mathbf{M}$ ), (iii) changes in the mix of intermediates (to be defined through matrix $\mathbf{Z}^{\mathbf{S}}$ ), (iv) and changes in the export structure $\left(\mathbf{e}^{\mathbf{S}}\right)$.

We define $\mathbf{M}$ as an $n x n$ matrix capturing the shares of foreign intermediates to total intermediates with $m_{i j}=z_{i j}^{i m p} / z_{i j}^{\text {tot }}$. We define a matrix with intermediate input shares as $\mathbf{Z}^{\mathbf{S}}=\mathbf{Z}_{\text {tot }}(\mathbf{I}-\hat{\mathbf{v}})^{-1} . \mathbf{Z}^{\mathbf{S}}$ is a matrix with normalised intermediate input coefficients (where each column sums to one). It follows that

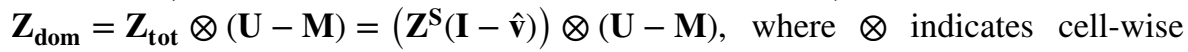


multiplication and $\mathbf{U}$ an $n x n$ matrix of ones. We can thus rewrite the formula for the VAX-D ratio as

$$
V A X D r=\mathbf{v}^{\prime}\left(\mathbf{I}-\left(\mathbf{Z}^{\mathbf{S}}(\mathbf{I}-\hat{\mathbf{v}})\right) \otimes(\mathbf{U}-\mathbf{M})\right)^{-1} \mathbf{e}^{\mathbf{S}}
$$

To decompose the change in the VAX-D ratio over time, we apply a polar decomposition following Dietzenbacher and Los (1998). We rewrite Eq. (7) as $V A X D r=\mathbf{f}\left(\mathbf{Z}^{\mathbf{S}}, \mathbf{v}, \mathbf{M}, \mathbf{e}^{\mathbf{S}}\right) .1$ and 0 indicate the respective time periods. It follows

$$
\Delta V A X D r=\mathbf{f}\left(\mathbf{Z}_{1}^{\mathbf{S}}, \mathbf{v}_{1}, \mathbf{M}_{1}, \mathbf{e}_{1}^{\mathbf{S}}\right)-\mathbf{f}\left(\mathbf{Z}_{0}^{\mathbf{S}}, \mathbf{v}_{0}, \mathbf{M}_{0}, \mathbf{e}_{0}^{\mathbf{S}}\right)
$$

The decomposition relies on the same principle as the well-known within-between decomposition of aggregate ratios (see e.g. Johnson and Noguera 2012). It measures the contribution of a change in one component while keeping the other components constant. Through subtracting and adding the same terms, we can extend (8) as follows:

$$
\begin{aligned}
\Delta V A X D r= & \mathbf{f}\left(\mathbf{Z}_{1}^{\mathbf{S}}, \mathbf{v}_{1}, \mathbf{M}_{1}, \mathbf{e}_{1}^{\mathbf{S}}\right)-\mathbf{f}\left(\mathbf{Z}_{0}^{\mathbf{S}}, \mathbf{v}_{1}, \mathbf{M}_{1}, \mathbf{e}_{1}^{\mathbf{S}}\right)+\mathbf{f}\left(\mathbf{Z}_{0}^{\mathbf{S}}, \mathbf{v}_{1}, \mathbf{M}_{1}, \mathbf{e}_{1}^{\mathbf{S}}\right)-\mathbf{f}\left(\mathbf{Z}_{0}^{\mathbf{S}}, \mathbf{v}_{0}, \mathbf{M}_{1}, \mathbf{e}_{1}^{\mathbf{S}}\right) \\
& +\mathbf{f}\left(\mathbf{Z}_{0}^{\mathbf{S}}, \mathbf{v}_{0}, \mathbf{M}_{1}, \mathbf{e}_{1}^{\mathbf{S}}\right)-\mathbf{f}\left(\mathbf{Z}_{0}^{\mathbf{S}}, \mathbf{v}_{0}, \mathbf{M}_{0}, \mathbf{e}_{1}^{\mathbf{S}}\right)+\mathbf{f}\left(\mathbf{Z}_{0}^{\mathbf{S}}, \mathbf{v}_{0}, \mathbf{M}_{0}, \mathbf{e}_{1}^{\mathbf{S}}\right)-\mathbf{f}\left(\mathbf{Z}_{0}^{\mathbf{S}}, \mathbf{v}_{0}, \mathbf{M}_{0}, \mathbf{e}_{0}^{\mathbf{S}}\right)
\end{aligned}
$$

or

$$
\begin{aligned}
\Delta V A X D r= & \mathbf{f}\left(\Delta \mathbf{Z}^{\mathbf{S}}, \mathbf{v}_{1}, \mathbf{M}_{1}, \mathbf{e}_{1}^{\mathbf{S}}\right)+\mathbf{f}\left(\mathbf{Z}_{0}^{\mathbf{S}}, \Delta \mathbf{v}, \mathbf{M}_{1}, \mathbf{e}_{1}^{\mathbf{S}}\right)+\mathbf{f}\left(\mathbf{Z}_{0}^{\mathbf{S}}, \mathbf{v}_{0}, \Delta \mathbf{M}, \mathbf{e}_{1}^{\mathbf{S}}\right) \\
& +\mathbf{f}\left(\mathbf{Z}_{0}^{\mathbf{S}}, \mathbf{v}_{0}, \mathbf{M}_{0}, \Delta \mathbf{e}^{\mathbf{S}}\right)
\end{aligned}
$$

Here, the change in $\mathbf{Z}^{\mathbf{S}}$ is weighted by end of period weights. We can also define a polar case in which the weights are from the beginning of the period:

$$
\begin{aligned}
\Delta V A X D r= & \mathbf{f}\left(\mathbf{Z}_{1}^{\mathbf{S}}, \mathbf{v}_{1}, \mathbf{M}_{1}, \mathbf{e}_{1}^{\mathbf{S}}\right)-\mathbf{f}\left(\mathbf{Z}_{1}^{\mathbf{S}}, \mathbf{v}_{1}, \mathbf{M}_{1}, \mathbf{e}_{0}^{\mathbf{S}}\right)+\mathbf{f}\left(\mathbf{Z}_{1}^{\mathbf{S}}, \mathbf{v}_{1}, \mathbf{M}_{1}, \mathbf{e}_{0}^{\mathbf{S}}\right)-\mathbf{f}\left(\mathbf{Z}_{1}^{\mathbf{S}}, \mathbf{v}_{1}, \mathbf{M}_{0}, \mathbf{e}_{0}^{\mathbf{S}}\right) \\
& +\mathbf{f}\left(\mathbf{Z}_{1}^{\mathbf{S}}, \mathbf{v}_{1}, \mathbf{M}_{0}, \mathbf{e}_{0}^{\mathbf{S}}\right)-\mathbf{f}\left(\mathbf{Z}_{1}^{\mathbf{S}}, \mathbf{v}_{0}, \mathbf{M}_{0}, \mathbf{e}_{0}^{\mathbf{S}}\right)+\mathbf{f}\left(\mathbf{Z}_{1}^{\mathbf{S}}, \mathbf{v}_{0}, \mathbf{M}_{0}, \mathbf{e}_{0}^{\mathbf{S}}\right)-\mathbf{f}\left(\mathbf{Z}_{0}^{\mathbf{S}}, \mathbf{v}_{0}, \mathbf{M}_{0}, \mathbf{e}_{0}^{\mathbf{S}}\right)
\end{aligned}
$$

or

$$
\begin{aligned}
\Delta V A X D r= & \mathbf{f}\left(\mathbf{Z}_{1}^{\mathbf{S}}, \mathbf{v}_{1}, \mathbf{M}_{1}, \Delta \mathbf{e}^{\mathbf{S}}\right)+\mathbf{f}\left(\mathbf{Z}_{1}^{\mathbf{S}}, \mathbf{v}_{1}, \Delta \mathbf{M}, \mathbf{e}_{0}^{\mathbf{S}}\right)+\mathbf{f}\left(\mathbf{Z}_{1}^{\mathbf{S}}, \Delta \mathbf{v}, \mathbf{M}_{0}, \mathbf{e}_{0}^{\mathbf{S}}\right) \\
& +\mathbf{f}\left(\Delta \mathbf{Z}^{\mathbf{S}}, \mathbf{v}_{0}, \mathbf{M}_{0}, \mathbf{e}_{0}^{\mathbf{S}}\right)
\end{aligned}
$$

We take the average of the polars, and write the following decomposition ${ }^{21}$ :

$$
\begin{aligned}
\Delta V A X D r= & \frac{1}{2}\left(\mathbf{f}\left(\Delta \mathbf{Z}^{\mathbf{S}}, \mathbf{v}_{0}, \mathbf{M}_{0}, \mathbf{e}_{0}^{\mathbf{S}}\right)+\mathbf{f}\left(\Delta \mathbf{Z}^{\mathbf{S}}, \mathbf{v}_{1}, \mathbf{M}_{1}, \mathbf{e}_{1}^{\mathbf{S}}\right)\right) \quad \text { contribution from } \Delta Z^{S} \\
& +\frac{1}{2}\left(\mathbf{f}\left(\mathbf{Z}_{1}^{\mathbf{S}}, \Delta \mathbf{v}, \mathbf{M}_{0}, \mathbf{e}_{0}^{\mathbf{S}}\right)+\mathbf{f}\left(\mathbf{Z}_{0}^{\mathbf{S}}, \Delta \mathbf{v}, \mathbf{M}_{1}, \mathbf{e}_{1}^{\mathbf{S}}\right)\right) \quad \text { contribution from } \Delta v \\
& +\frac{1}{2}\left(\mathbf{f}\left(\mathbf{Z}_{1}^{\mathbf{S}}, \mathbf{v}_{1}, \Delta \mathbf{M}, \mathbf{e}_{0}^{\mathbf{S}}\right)+\mathbf{f}\left(\mathbf{Z}_{0}^{\mathbf{S}}, \mathbf{v}_{0}, \Delta \mathbf{M}, \mathbf{e}_{1}^{\mathbf{S}}\right)\right) \quad \text { contribution from } \Delta M \\
& +\frac{1}{2}\left(\mathbf{f}\left(\mathbf{Z}_{1}^{\mathbf{S}}, \mathbf{v}_{1}, \mathbf{M}_{1}, \Delta \mathbf{e}^{\mathbf{S}}\right)+\mathbf{f}\left(\mathbf{Z}_{0}^{\mathbf{S}}, \mathbf{v}_{0}, \mathbf{M}_{0}, \Delta \mathbf{e}^{\mathbf{S}}\right)\right) \quad \text { contribution from } \Delta e^{S}
\end{aligned}
$$

\footnotetext{
${ }^{21}$ In principle, with $n$ components we can define $n$ ! alternative decompositions. These will be numerically very close as long as changes in one of the components are not extreme.
} 


\section{References}

Bai, J., \& Perron, P. (1998). Estimating and testing linear models with multiple structural changes. Econometrica, 66, 47-78. https://doi.org/10.2307/2998540.

Bai, J., \& Perron, P. (2003). Computation and analysis of multiple structural change models. Journal of Applied Econometrics, 18, 1-22. https://doi.org/10.1002/jae.659.

Bai, J., \& Perron, P. (2006). Multiple structural change models: a simulation analysis. In D. Corbae, S. N. Durlauf, B. E. Hansen (Ed.), Econometric theory and practice: Frontiers of analysis and applied research (pp. 212-237). Cambridge University Press. https://doi.org/10.1017/CBO978113916486 3.010 .

Baldwin, R., \& Lopez-Gonzalez, J. (2015). Supply-chain trade: A portrait of global patterns and several testable hypotheses. The World Economy, 38, 1682-1721. https://doi.org/10.1111/ twec. 12189.

Bems, R., Johnson, R. C., \& Yi, K. M. (2011). Vertical linkages and the collapse of global trade. American Economic Review, 101(3), 308-312.

Berg, A., Ostry, J. D., \& Zettelmeyer, J. (2012). What makes growth sustained? Journal of Development Economics, 98, 149-166.

Brandt, L., Van Biesebroeck, J., Wang, L., \& Zhang, Y. (2017). WTO accession and performance of Chinese manufacturing firms. American Economic Review, 107, 2784-2820.

Del Prete, D., Giovannetti, G., \& Marvasi, E. (2017). Global value chains participation and productivity gains for North African firms. Review of World Economics, 153(4), 675-701.

Dietzenbacher, E., \& Los, B. (1998). Structural decomposition techniques: Sense and sensitivity. Economic Systems Research, 10(4), 307-324.

Duan, Y., Dietzenbacher, E., Jiang, X., Chen, X., \& Yang, C. (2018). Why has China's vertical specialization declined? Economic Systems Research, 30, 1-23.

Feenstra, R. C. (1998). Integration of trade and disintegration of production in the global economy. Journal of Economic Perspectives, 12(4), 31-50.

Feenstra, R. C., Inklaar, R., \& Timmer, M. P. (2015). The next generation of the Penn World Table. American Economic Review, 105, 3150-3182. https://doi.org/10.1257/aer.20130954.

Feenstra, R. C., Lipsey, R. E., Deng, H., Ma, A. C., \& Mo, H. (2005). World trade flows: 1962-2000. National Bureau of Economic Research, No. w11040. https://doi.org/10.3386/w11040.

Foster-McGregor, N., Isaksson, A., \& Kaulich, F. (2014). Importing, exporting and performance in subSaharan African manufacturing firms. Review of World Economics, 150(2), 309-336.

Gaulier, G., \& Zignago, S. (2010). Baci: International trade database at the product-level (the 19942007 version) (CEPII Working Paper No. 2010-23).

Hirschman, A. O. (1958). The strategy of economic development. New Haven: Yale University Press.

Hummels, D., Ishii, J., \& Yi, K. M. (2001). The nature and growth of vertical specialization in world trade. Journal of International Economics, 54, 75-96. https://doi.org/10.1016/S0022 -1996(00)00093-3.

Imbs, J., \& Wacziarg, R. (2003). Stages of diversification. American Economic Review, 93(1), 63-86.

International Monetary Fund (IMF). (2018). International financial statistics database.

Johnson, R. C. (2014). Five facts about value-added exports and implications for macroeconomics and trade research. Journal of Economic Perspectives, 28(2), 119-142.

Johnson, R. C. (2017). Measuring global value chains. National Bureau of Economic Research, No. w24027.

Johnson, R. C., \& Noguera, G. (2012). Accounting for intermediates: Production sharing and trade in value added. Journal of International Economics, 86(2), 224-236.

Johnson, R. C., \& Noguera, G. (2017). A portrait of trade in value added over four decades. Review of Economics and Statistics, 99(5), 896-911.

Kar, S., Pritchett, L., Raihan, S., \& Sen, K. (2013). Looking for a break: Identifying transitions in growth regimes. Journal of Macroeconomics, 38, 151-166.

Kee, H. L., \& Tang, H. (2016). Domestic value added in exports: Theory and firm evidence from China. American Economic Review, 106, 1402-1436. https://doi.org/10.1257/aer.20131687.

Koopman, R., Wang, Z., \& Wei, S. J. (2012). Estimating domestic content in exports when processing trade is pervasive. Journal of Development Economics, 99, 178-189. https://doi.org/10.1016/j.jdeve co.2011.12.004. 
Koopman, R., Wang, Z., \& Wei, S. J. (2014). Tracing value-added and double counting in gross exports. American Economic Review, 104, 459-494. https://doi.org/10.1257/aer.104.2.459.

Lenzen, M., Moran, D., Kanemoto, K., \& Geschke, A. (2013). Building Eora: A global multi-region input-output database at high country and sector resolution. Economic Systems Research, 25, 20-49. https://doi.org/10.1080/09535314.2013.769938.

Lind, J. T., \& Mehlum, H. (2010). With or without U? The appropriate test for a U-shaped relationship. Oxford Bulletin of Economics and Statistics, 72, 109-118. https://doi.org/10.111 1/j.1468-0084.2009.00569.x.

Los, B., \& Timmer, M. P. (2018). Indicators for bilateral trade dependence: A unified framework, Draft prepared for CRIW conference on the challenges of globalization in the measurement of national accounts, 9/10 March 2018.

Los, B., Timmer, M. P., \& de Vries, G. J. (2016). Tracing value-added and double counting in gross exports: Comment. American Economic Review, 106, 1958-1966. https://doi.org/10.1257/aer.20140 883.

Milberg, W., Jiang, X., \& Gereffi, G. (2014). Industrial policy in the era of vertically specialized industrialization. In J. Salazar-Xirinachs, I. Nübler, R. Kozul-Wright (Ed.), Transforming economies: Making industrial policy work for growth, jobs and development. Geneva. http://hdl.handle.net/10161 /11422.

Miroudot, S., \& Cadestin, C. (2017). Services in global value chains: From inputs to value-creating activities (OECD Trade Policy Papers No. 197). Paris: OECD Publishing. https://doi.org/10.1787/465f0 d8b-en.

Narayanan, B. \& Walmsley, T. L. (2008). Global trade, assistance, and production: The GTAP 7 data base. Center for Global Trade Analysis, Purdue University.

OECD. (2015). OECD Inter-country input-output (ICIO) tables, 2015 edition.

Pritchett, L., Sen, K., Kar, S., \& Raihan, S. (2016). Trillions gained and lost: Estimating the magnitude of growth episodes. Economic Modelling, 55, 279-291.

Chenery, H. B., Robinson, S., \& Syrquin, M. (1986). Industrialization and growth: A comparative study. Washington, DC: The World Bank.

Timmer, M. P., \& de Vries, G. J. (2009). Structural change and growth accelerations in Asia and Latin America: A new sectoral data set. Cliometrica, 3, 165-190. https://doi.org/10.1007/s1169 8-008-0029-5.

Timmer, M. P., Dietzenbacher, E., Los, B., Stehrer, R., \& de Vries, G. J. (2015). An illustrated user guide to the World Input-Output Database: The case of global automotive production. Review of International Economics, 4, 575-605. https://doi.org/10.1111/roie.12178.

Timmer, M. P., Miroudot, S., \& de Vries, G. J. (2018). Functional specialisation in trade. Journal of Economic Geography, 19(1), 1-30.

United Nation Industrial Development Organization (UNIDO). (2016). INDSTAT2, Industrial Statistics Database.

United Nations (UN). (2015a). National accounts official country data, United Nations Statistics Division. Retrieved January 20, 2016, from http://unstats.un.org/unsd/nationalaccount/default.asp.

United Nations (UN). (2015b). National accounts estimates of main aggregates, United Nations Statistics Division. Retrieved January 20, 2016, from http://unstats.un.org/unsd/nationalaccount/default.asp.

United Nations (UN). (2015c). Classification files. United Nations Statistics Division. Retrieved January 20, 2016, from http://unstats.un.org/unsd/cr/registry/regdnld.asp?Lg=1.

World Bank. (2018a). Oil rents (\% of GDP). https://data.worldbank.org/indicator/NY.GDP.PETR.RT.ZS.

Wu, H. X. \& Ito, K. (2015). Reconstructing China's supply-use and input-output tables in time series (RIETI Discussion Papers 15-E-004).

Yi, K. M. (2003). Can vertical specialization explain the growth of world trade? Journal of Political Economy, 111(1), 52-102.

Publisher's Note Springer Nature remains neutral with regard to jurisdictional claims in published maps and institutional affiliations. 